\title{
La Sentencia de 28 de enero de 2009 del Tribunal Supremo sobre el silencio administrativo en las licencias urbanísticas
}

\author{
$\mathrm{M}^{\mathrm{a}}$ del Carmen Ortiz de Tena \\ Profesora Titular de Derecho Administrativo \\ Universidad de Sevilla
}

\begin{abstract}
Damos cuenta de la importante Sentencia del Tribunal Supremo de 28 de enero de 2009, que resuelve un recurso de casación en interés de ley, y fija como doctrina legal que el artículo 242.6 del Texto Refundido de la Ley sobre Régimen del Suelo y Ordenación Urbana, aprobado por Real Decreto Legislativo 1/1992, de 26 de junio, y el artículo 8.1 b), último párrafo, del Texto Refundido de la Ley del Suelo aprobado por Real Decreto Legislativo 2/2008, de 20 de junio, son normas con rango de leyes básicas estatales, en cuya virtud y conforme a lo dispuesto en el precepto estatal, también básico, contenido en el artículo 43.2 de la Ley de 30/1992, de 26 noviembre de Régimen Jurídico de las Administraciones Públicas y del Procedimiento Administrativo Común, modificado por la Ley 4/1999, de 13 enero, no pueden entenderse adquiridas por silencio administrativo licencias en contra de la ordenación territorial o urbanística.
\end{abstract}

Como es sabido, el juego del silencio positivo establecido como regla general en la Ley 30/1992 había suscitado algunas dudas sobre la posibilidad de adquirir o no licencias urbanísticas amparándose precisamente en la falta de respuesta expresa de la Administración. Ello produjo situaciones en las que la Administración se veía obligada a revisar de oficio licencias adquiridas de forma presunta y en contra de la legalidad urbanística y el planeamiento.

El recurso de casación que ha dado lugar a la Sentencia comentada se basa en que la resolución pronunciada por la Sala de instancia acerca de la adquisición por silencio positivo de licencias en contra de la legislación y planeamiento urbanístico es errónea y gravemente dañosa para el interés general. La Sentencia citada estima el recurso, y zanja la cuestión de la eficacia del silencio positivo para estos casos. 
Sentencia de 28 de enero de 2009 del Tribunal Supremo (Sala de lo contencioso-administrativo, sección $5^{\mathrm{a}}$ ). Recurso de casación en interés de la Ley $n^{\circ} 45 / 2007$. Ponente. Excmo. Sr. Jesús Ernesto Peces Morate

En la Villa de Madrid, a veintiocho de enero de dos mil nueve.

Visto por la Sala Tercera (Sección Quinta) del Tribunal Supremo, constituida por los Magistrados Excmos. Sres. anotados al margen, el presente recurso de casación en interés de la Ley, sostenido por el Procurador Don Juan Ignacio Ávila del Hierro, en nombre y representación del Ayuntamiento de Málaga, contra la sentencia pronunciada, con fecha 29 de marzo de 2007, por la Sala de lo Contencioso-Administrativo del Tribunal Superior de Justicia de Andalucía, con sede en Málaga, en el recurso de apelación 8/2003, sustanciado contra la sentencia número 190/02, de fecha 15 de julio de 2002, dictada por el Juzgado de lo Contencioso-Administrativo número cuatro de Málaga, habiendo comparecido, como recurridos, Don Guillermo y Don Juan Ramón, representados por el Procurador Don Isacio Calleja García, y han sido oídos el Abogado del Estado, en la representación que le es propia, y el Ministerio Fiscal.

\section{ANTECEDENTES DE HECHO}

\section{PRIMERO}

El Juzgado de lo Contencioso-Administrativo número cuatro de Málaga dictó, con fecha 15 de julio de 2002, sentencia en el recurso contencioso-administrativo $\mathrm{n}^{\circ} 494 / 2001$, cuya parte dispositiva es del tenor literal siguiente: «FALLO: Que desestimando el recurso contencioso-administrativo interpuesto por el Procurador Don José Luis Torres Beltrán, en representación de Don Guillermo y Don Juan Ramón, contra la desestimación por silencio del recurso formulado contra la resolución de la Gerencia Municipal de Urbanismo, del Ayuntamiento de Málaga, de 09/03/01, debo declarar y declaro ser conforme a derecho la resolución impugnada, sin expresa condena en costas a ninguna de las partes».

\section{SEGUNDO}

Dicha sentencia se basa, entre otros, en el siguiente fundamento jurídico quinto: «En cuanto a la alegación referente a la adquisición de la licencia por silencio positivo no resulta de aplicación el Art. 43 L 30/09 SIC en su redacción dada por L 4/99 esgrimido por los recurrentes sino la normativa específica de la Ley del Suelo y RSCL. Al respecto, si la obra supone ir contra lo establecido 
en el planeamiento urbanístico, lo que acontece en este caso al ejecutarse obras para las que no se contaba con la preceptiva licencia e incumpliendo la norma urbanística como se ha visto, conforme al Art. 242-6 LS en ningún caso se entenderán adquiridas por silencio administrativo licencias en contra de la legislación o planeamiento urbanístico, incluso aun cuando se tratara de licencia de una obra menor o de otro objeto como es la de primera ocupación, para los que el Art. 9-5 y 7 c) permitiría operar el silencio positivo (SSTS 25/02/92, 26/05/89 y 19/03/89 SIC). Por otra parte, la licencia de primera ocupación, por su íntima conexión con la licencia de obras o edificación, ha de estar sometida al mismo régimen de silencio administrativo que la licencia de obras de la que traiga causa, y en el caso contemplado, tratándose de una licencia de obra mayor, hubiera sido necesario seguir los trámites del Art. 9-7 a) RSCL».

\section{TERCERO}

Apelada la indicada sentencia por los demandantes ante la Sala de lo Contencioso-Administrativo del Tribunal Superior de Justicia de Andalucía, con sede en Málaga, se sustanció, con el número 8/2003, el correspondiente recurso de apelación y la referida Sala dictó, con fecha 29 de marzo de 2007, sentencia, cuya parte dispositiva es del tenor literal siguiente: «FALLAMOS: Estimar el recurso interpuesto contra la sentencia identificada en el fundamento jurídico primero de esta resolución, que anulamos. Estimando el recurso contencioso interpuesto, declarando el derecho de los recurrentes a obtener la licencia al haberse producido silencio positivo con el alcance de lo escrito en el fundamento jurídico quinto de esta sentencia, párrafo último, es decir sin que la Sala se pronuncie sobre la corrección jurídica urbanística de lo obtenido por silencio. Sin hacer especial pronunciamiento respecto del abono de las costas devengadas en este proceso».

\section{CUARTO}

Esta sentencia se basa, entre otros, en el siguiente fundamento jurídico segundo: «La única cuestión que debe resolverse en esta apelación es, por deseo expreso de las partes, la eficacia del silencio positivo cuando estamos ante una licencia urbanística y debemos aplicar la regulación del silencio tras la reforma realizada en la Ley 30/1992 por Ley 4/1999. Escenario en el que no hay pronunciamiento jurisprudencial de nuestro Tribunal Supremo. Sobre la misma cuestión se ha pronunciado el Tribunal Superior de Justicia de Valencia en sentencia de 24.05.2005, en ella se dice: “...Esta materia ya ha sido estudiada por esta Sala en diversas sentencias partiendo de la doctrina establecida para "unificación de doctrina" en la sentencia 1487/2002 de 4 de noviembre 
(Rec. Casa. Unif. Doctri. 1/2002) y que ha sido seguido por otras sentencias de esta Sala y Sección Tercera 14.01.2004, 1.12.2004 y 2.12.2004 (Rec. 1773/2000 y 389/2001). La Ley 30/1992, de 26 de Noviembre, de Régimen Jurídico de las Administraciones Públicas y Procedimiento Administrativo Común, reformada por la Ley 4/1999, parte de una premisa muy clara en el Art. 43.2 cuando se ha iniciado un procedimiento por solicitud del interesado: “... Los interesados podrán entender estimadas por silencio administrativo sus solicitudes en todos los casos, salvo que una norma con rango de Ley o norma de Derecho Comunitario Europeo establezca lo contrario..." y esa estimación de las peticiones de los interesados se produce según el Art. 43.5 "...desde el vencimiento del plazo máximo en el que debe dictarse y notificarse la resolución expresa sin que esta se haya producido. En nuestro caso, no cabe dudas de que el plazo era de tres meses (plazo ajustado al Art. 42.2 de la Ley $30 / 1992$ ) y que los efectos del silencio administrativo eran positivos (Art. 43.2) pues la solicitud se hace el 4.3.2002 y no se le notifica la resolución denegatoria hasta el 11.12.2002; como muestra cabe decir que presentada la solicitud en marzo de 2002 el Ayuntamiento de Benaguacil no mueve un papel hasta el 2.08.2002 con el informe del Ingeniero Técnico Municipal y posterior de 4.10.2003 incomprensiblemente deja el último informe el que debió ser primero, el urbanístico, que se hace el 28.10.2002. Con el razonamiento del Ayuntamiento, presentada la solicitud del particular el 4.3.2002 debió emitir informe el Arquitecto Municipal y, sin más trámite, denegar la licencia si entendía que pugnaba con las normas urbanísticas, de nada sirve informar sobre un proyecto que puede ser magnífico técnicamente si las normas urbanísticas van a impedir necesariamente que se lleve a la práctica. Con los parámetros que se acaban de citar es obvio que el 5.06.2002 el demandante había obtenido la licencia de actividad inocua por silencio administrativo positivo y según el Art. 43.3 "La estimación por silencio administrativo tiene a todos los efectos la consideración de acto administrativo finalizador del procedimiento... y continúa el Art. 43.5: ...Los actos administrativos producidos por silencio administrativo se podrán hacer valer tanto ante la Administración como ante cualquier persona física o jurídica, pública o privada. Los mismos producen efectos desde el vencimiento del plazo máximo en el que debe dictarse y notificarse la resolución expresa sin que la misma se haya producido, y su existencia puede ser acreditada por cualquier medio de prueba admitido en Derecho...”. Ahora bien, podemos preguntarnos qué efectos tiene una resolución administrativa tardía que vaya contra el silencio administrativo positivo; en teoría, no puede darse pues el Art. 43.3 ya hemos visto que producido el silencio administrativo positivo el "procedimiento administrativo ha finalizado". La Ley 4/1999 modificadora de la Ley 30/1992, lo que pretende es que se analice el silencio administrativo en abstracto, si por la exis- 
tencia de una resolución posterior a la que debe entenderse adquirida una autorización por silencio administrativo positivo dejase de ser operativa, sencillamente estaríamos haciendo una interpretación que derogaría y haría superflua la propia reforma efectuada por Ley 4/1999; si nos fijamos en la exposición de motivos veda esta posibilidad: “...Se trata de regular esta capital institución del procedimiento administrativo de forma equilibrada y razonable, por lo que se suprime la certificación de actos presuntos que, como es sabido, permitía a la Administración, una vez finalizados los plazos para resolver y antes de expedir la certificación o que transcurriera el plazo para expedirla, dictar un acto administrativo expreso aun cuando resultara contrario a los efectos del silencio ya producido. Por todo ello, el silencio administrativo positivo producirá un verdadero acto administrativo eficaz, que la Administración pública sólo podrá revisar de acuerdo con los procedimientos de revisión establecidos en la Ley...." y, en consonancia con la exposición de motivos el Art. 43.4.a) sólo permite a la Administración resolver confirmando el silencio administrativo positivo, caso contrario, cuando la Administración se percate que han pasado los plazos y que el ciudadano ha obtenido autorización o cualquier otro derecho por silencio administrativo positivo debe acudir a los procedimientos de revisión previstos en la Ley, nunca se le permite dictar resolución expresa contraria al silencio administrativo positivo (el procedimiento ha finalizado: Art.43.3). Por ello, al enjuiciar el fondo del proceso el prisma que debe adoptarse es ignorar la resolución expresa, si el actor tiene razón en su pretensión el Tribunal condenará a la Administración a entregarle el certificado, caso contrario puede y debe analizar la resolución expresa de la Administración dependiendo de los motivos de impugnación y planteamiento que haga el recurrente. El paso siguiente será determinar qué efectos jurídicos debemos dar a la Disposición Adicional Cuarta de la Ley de las Cortes Valencianas 6/1994, de 15 de noviembre, reguladora de la Actividad Urbanística, cuando afirma: “...En ningún caso se entenderán adquiridas por silencio administrativo facultades en contra de las prescripciones de esta Ley, de los Planes, Proyectos, Programas u Ordenanzas o, en general, en términos contrarios, opuestos o disconformes con las previsiones de la ordenación urbanística. La solicitud de licencia urbanística que no sea resuelta por el Ayuntamiento dentro de los plazos legales, sin perjuicio de las prórrogas que sean procedentes, se entenderá estimada, salvo que su contenido sea constitutivo de contravención grave y manifiesta de la ordenación urbanística, en cuyo caso se entenderá desestimada...". El precepto de gran raigambre en nuestra legislación urbanística, baste la lectura del Art. 242.6 del Real Decreto Legislativo 1/1992, de 26 de junio, por el que se aprueba el texto refundido de la Ley sobre el régimen del Suelo y Ordenación Urbana, como otros que le precedieron a nivel estatal y que con mimético contenido puede leerse en las diferentes leyes del 
suelo de las comunidades autónomas, debe ser interpretado con lo expuesto sobre la Ley 30/1992 modificada por Ley 30/1999 SIC. Efectivamente hemos concluido: El procedimiento de otorgamiento de licencia ha finalizado una vez producido el silencio administrativo positivo. El particular puede hacer valer su licencia ante cualquier administración o particular. En consecuencia con estas dos premisas "...no puede dictar ninguna resolución denegando la licencia..”, sin que nos pueda llevar a engaño el Art. 43.4.a) “...En los casos de estimación por silencio administrativo, la resolución expresa posterior a la producción del acto sólo podrá dictarse de ser confirmatoria del mismo...”, la Administración en este caso no reabre el procedimiento administrativo terminado por silencio administrativo positivo ni concede ningún derecho al particular ni facultad que no tenga con el silencio administrativo positivo simplemente le certifica lo que la Ley le ha concedido, que puede tener trascendencia para el particular en ámbitos como solicitar créditos bancarios para instalaciones, etc. pero son efectos de índole práctico y operativo para una empresa o particular no jurídicos. Por tanto, si un particular cuenta con una licencia obtenida por "silencio administrativo positivo" que la Administración no puede desconocer ni resolver en contra dentro del concreto procedimiento al haber finalizado, caso de entender que es perjudicial para el interés público, no le queda otra opción que acudir a los procedimientos de revisión de oficio y adoptar como medida cautelar la suspensión de la licencia obtenida por silencio administrativo positivo, este es el sentido de la Disposición Adicional Cuarta de la Ley de las Cortes Valencianas 6/1994, de 15 de noviembre, reguladora de la Actividad Urbanística, dar un mandato a la Administración para que, caso de haberse obtenido licencia por silencio administrativo positivo, impida la obtención de facultades que la Ley o los instrumentos de planeamiento no le conceden, en modo alguno, el precepto supone una derogación de los procedimientos de la Ley 30/1992 modificada por Ley 4/1999. Situación que en nada difiere a la posición que debe adoptar la Administración cuando otorga una licencia de forma errónea. La interpretación que hace la Sala no es novedosa y puede encontrarse en la legislación urbanística de diversas Comunidades Autónomas, tomemos el art. 5.2 de la Ley Catalana 2/2002, de 14 de marzo, de urbanismo, afirma “...En ningún caso pueden considerarse adquiridas por silencio administrativo facultades urbanísticas que contravengan esta Ley o el planeamiento urbanístico..." pero el Art. 180.2 cuando pretende materializar la imposibilidad de adquirir facultades por silencio administrativo es muy claro "...La competencia y el procedimiento para otorgar y denegar las licencias urbanísticas se ajustan a lo establecido en la legislación de régimen local. El sentido positivo del silencio administrativo en la materia se entiende sin perjuicio de lo dispuesto en el Art. 5.2 y en el marco de lo establecido en la legislación aplicable sobre procedimiento administrativo común...”. En el mismo 
sentido el Art. 176 de la Ley Aragonesa 5/1999, de 25 de marzo, Urbanística, “...Transcurrido el plazo de resolución sin haberse notificado ésta, el interesado podrá entender estimada su petición por silencio administrativo, en los términos establecidos en la legislación del procedimiento administrativo común. En ningún caso se entenderán adquiridas por silencio administrativo licencias en contra de la legislación o del planeamiento urbanístico...". Por tanto, se estima el recurso en el sentido de anular la denegación de la licencia de forma expresa como la desestimación presunta del recurso de reposición. No obstante, en el suplico de la demanda y recurso de apelación existe una petición "...acuerde conceder a mi mandante la mencionada licencia de apertura solicitada el 04.03.2002...", la Sala no concede la licencia sino que reconoce que la ha obtenido por "silencio administrativo positivo..."».

\section{QUINTO}

Devueltas las actuaciones por la Sala al Juzgado que dictó la sentencia en primera instancia con testimonio de la pronunciada en apelación, se notificó a las partes y concretamente al Ayuntamiento de Málaga con fecha 18 de mayo de 2007.

\section{SEXTO}

Con fecha 10 de septiembre de 2007 compareció ante esta Sala del Tribunal Supremo el Procurador Don Juan Ignacio Ávila del Hierro, en nombre y representación del Ayuntamiento de Málaga, al mismo tiempo que presentó escrito de interposición de recurso de casación en interés de la ley, alegando que la sentencia contiene una doctrina errónea, ya que en ella se declara que, a partir de la modificación de la Ley de Régimen Jurídico de las Administraciones Públicas y del Procedimiento Administrativo Común por Ley 4/1999, el silencio administrativo es siempre positivo sin que resulte impedimento para ello lo dispuesto en el vigente artículo 242.6 del Texto Refundido de la Ley sobre Régimen del Suelo y Ordenación Urbana, de manera que la Sala del Tribunal Superior de Justicia de Andalucía, con sede en Málaga, considera que, una vez producido el acto presunto de concesión de la licencia en virtud de la figura del silencio positivo, la Administración municipal no puede dictar una resolución denegatoria de la misma sino que tiene que acudir a la revisión de oficio de la licencia obtenida, lo que es contrario a la doctrina jurisprudencial emanada de las sentencias que se citan y transcriben de la Sala Tercera del Tribunal Supremo, y, además, resulta gravemente dañosa para el interés general porque los juzgados inferiores en grado quedan vinculados por esa doctrina errónea sentada por la Sala en apelación y ello conduciría a una situación de 
anarquía e ilegalidad en un ámbito tan sensible y de trascendencia social como es el urbanismo, pues se deja sin efecto el precepto contenido en el artículo 242.6 del Texto Refundido de la Ley del Suelo de 1992, que tiene plena vigencia conforme a lo establecido en las Disposiciones derogatorias de las Leyes 6/1998 y 8/2007, de 28 de mayo, posterior ésta a la Ley 4/1999, sin que pueda aceptarse que lo dispuesto en el referido artículo 242.6 del Texto Refundido de la Ley de Suelo de 1992 se cumple utilizando los procedimientos de revisión de oficio previstos en la Ley de Régimen Jurídico de las Administraciones Públicas y del Procedimiento Administrativo Común, y así se termina con la súplica de que se dicte sentencia por esta Sala del Tribunal Supremo, en la que se declare, como doctrina legal, que «el artículo 242.6 del Texto Refundido de la Ley sobre el Régimen del Suelo y Ordenación Urbana (TRLS, aprobado por el R.D. Legislativo 1/1992, de 26 de junio) es una norma con rango de ley en virtud de la cual, conforme a lo dispuesto en el artículo 43.2 de la Ley 30/1992, de 26 de noviembre, de Régimen Jurídico de las Administraciones Públicas y del Procedimiento Administrativo Común, no se permite adquirir por silencio administrativo licencias en contra de la legislación o del planeamiento urbanístico», adjuntándose testimonio de la sentencia recurrida y certificación de la fecha de notificación de la misma al Ayuntamiento de Málaga.

\section{SÉPTIMO}

Mediante providencia de 15 de noviembre de 2007 se ordenó reclamar las actuaciones al Tribunal que dictó la sentencia recurrida y que se emplazase a cuantos hubiesen sido parte en las mismas para que, en el plazo de quince días, pudiesen comparecer, lo que llevó a cabo aquél y, con fecha 21 de enero de 2008, compareció ante esta Sala del Tribunal Supremo el Procurador Don Isacio Calleja García, en nombre y representación de Don Guillermo y Don Juan Ramón, al que se tuvo por comparecido y parte en la representación ostentada, al mismo tiempo que, accediendo a lo solicitado por el representante procesal del Ayuntamiento de Málaga, se libró oficio a este Ayuntamiento para que remitiese el expediente administrativo relativo al objeto del proceso sustanciado en primera y segunda instancia, y, una vez recibido éste así como las actuaciones seguidas ante el Juzgado y la Sala del Tribunal Superior de Justicia, se dio traslado del escrito de interposición al representante procesal de los comparecidos como recurridos a fin de que alegase lo que estimase procedente, quien, con fecha 8 de septiembre de 2008, presentó escrito en el que, sustancialmente, por las mismas razones expresadas en la sentencia recurrida, con algunas consideraciones añadidas respecto del silencio de la Administración sólo imputable a ella, terminó suplicando que se desestimase el recurso interpuesto y que se declarase no haber lugar a declarar la doctrina legal propuesta. 


\section{OCTAVO}

Conferido el traslado, con fecha 17 de septiembre de 2008, al Abogado del Estado para que, en el plazo de treinta días, formulase las alegaciones que tuviese por conveniente, éste presentó escrito en el que aduce que, si bien la Administración recurrente tiene razón desde el punto de vista material, el recurso no es estimable porque existe doctrina legal derivada de reiterada jurisprudencia, según la cual no cabe adquirir por silencio licencias en contra de la legalidad y el planeamiento urbanístico, licencias que, en cualquier caso, serían nulas de pleno derecho conforme al artículo $62.1 \mathrm{f}$ de la Ley de Régimen Jurídico de las Administraciones Públicas y del Procedimiento Administrativo Común, de modo que, a pesar de ser errónea la doctrina de la sentencia de la Sala del Tribunal Superior de Justicia, no cabe combatirla a través del recurso de casación en interés de la ley.

\section{NOVENO}

Seguidamente se pasaron las actuaciones al Ministerio Fiscal para que emitiese dictamen en el plazo de diez días, lo que efectuó con fecha 14 de noviembre de 2008, en el que considera que el recurso en interés de la Ley debe ser desestimado con imposición de costas a la Administración recurrente por cuanto, aunque la tesis de la Sala sentenciadora es errónea, existe una doctrina jurisprudencial consolidada, según la cual el silencio administrativo positivo no opera cuando la licencia solicitada es contraria a la normativa urbanística, de manera que la doctrina legal que se propugna es la que ya tiene establecida la jurisprudencia.

\section{DÉCIMO}

Emitido el dictamen por el Ministerio Fiscal, quedaron las actuaciones pendientes de señalamiento cuando por turno correspondiese, a cuyo fin se fijó para votación y fallo el día 14 de enero de 2009, en que tuvo lugar con observancia en su tramitación de las reglas establecidas por la Ley.

Siendo Ponente el Excmo. Sr. D. JESÚS ERNESTO PECES MORATE,

\section{FUNDAMENTOS DE DERECHO}

\section{PRIMERO}

La representación procesal del Ayuntamiento de Málaga sostiene que la sentencia pronunciada, con fecha 29 de marzo de 2007, por la Sala de lo Con- 
tencioso-Administrativo del Tribunal Superior de Justicia de Andalucía, con sede en Málaga, en el recurso de apelación 8/2003, al declarar que las licencias urbanísticas se adquieren por silencio positivo, aunque sean contrarias al ordenamiento urbanístico, en contra de lo establecido categóricamente por el artículo 242.6 del Texto Refundido de la Ley del Suelo y Ordenación Urbana, aprobado por Real Decreto Legislativo 1/1992, de 26 de junio, así como de la doctrina jurisprudencial que lo interpreta, recogida en las sentencias de esta Sala del Tribunal Supremo que se citan, es errónea y gravemente dañosa para los intereses generales por cuanto genera, al tener que ser aplicada por los Juzgados de lo Contencioso-Administrativo del territorio, una situación de anarquía e ilegalidad en un ámbito tan sensible y de tanta trascendencia social como es el urbanismo.

En la mencionada sentencia, la Sala de lo Contencioso-Administrativo del Tribunal Superior de Justicia de Andalucía, con sede en Málaga, declara, en síntesis, que la licencia urbanística, a que se contrajo el pleito sustanciado, al haber transcurrido el plazo marcado por la ley para que el Ayuntamiento resolviese, se adquirió por silencio positivo, por lo que anula la sentencia pronunciada por el Juzgado de lo Contencioso-Administrativo que había considerado que, conforme a lo establecido en el artículo 242.6 del Texto Refundido de la Ley del Suelo de 1992, por ser la licencia pedida al Ayuntamiento contraria al ordenamiento urbanístico no podía entenderse adquirida por silencio administrativo.

\section{SEGUNDO}

Tanto el Ministerio Fiscal como el Abogado del Estado aducen en sus respectivos informes que, aun cuando la tesis de la Sala de lo Contencioso-Administrativo del Tribunal Superior de Justicia es errónea, al existir jurisprudencia consolidada en sentido claramente contrario al de dicha Sala sentenciadora, no es cauce adecuado el recurso de casación en interés de la ley para fijar una doctrina legal que ya existe y que ha sido infringida por aquélla.

No podemos aceptar este planteamiento porque, aun cuando es cierto que la jurisprudencia de esta Sala del Tribunal Supremo ha mantenido que en ningún caso pueden entenderse adquiridas por silencio administrativo licencias en contra del ordenamiento urbanístico, no es menos cierto que el criterio del Tribunal a quo se basa en la modificación introducida en el artículo 43.2 de la Ley de Régimen Jurídico de las Administraciones Públicas y del Procedimiento Administrativo Común por la Ley 4/1999, de 13 de enero, según la cual, a su parecer, procede separarse de aquella doctrina jurisprudencial 
construida sobre unas premisas normativas que han desaparecido al promulgarse la mentada modificación, que configura el silencio como positivo en todo caso, también respecto de las licencias urbanísticas contrarias a la legislación o al ordenamiento urbanístico, que sólo tienen un cauce de corrección a través de la correspondiente revisión por la propia Administración como conducta obligada para ésta.

Aunque esta misma Sala y Sección del Tribunal Supremo se ha pronunciado repetidamente sobre los efectos del silencio respecto de las licencias urbanísticas, nunca examinó como cuestión central si, a partir de la nueva redacción del artículo 43 de la Ley de Régimen Jurídico de las Administraciones Públicas y del Procedimiento Administrativo Común dada por la Ley 4/1999, de 13 de enero, el régimen del silencio en relación con las licencias urbanísticas es el mismo que con anterioridad a esa modificación, razón por la que, en contra del parecer del Ministerio Fiscal y del Abogado del Estado, debemos entrar a conocer del recurso de casación en interés de la ley deducido por la representación procesal del Ayuntamiento de Málaga.

\section{TERCERO}

La Sala sentenciadora se remite, en apoyo de su tesis, a lo declarado por la Sala de lo Contencioso-Administrativo del Tribunal Superior de Justicia de la Comunidad Valenciana en varias sentencias, entre las que tenemos a la vista una de fecha 24 de noviembre de 2006 (recurso de apelación 184/2006), a la que se formuló un muy razonado voto particular en sentido opuesto.

También justifica su decisión la Sala de Málaga con lo establecido por la Ley de Ordenación Urbanística de Andalucía 7/2002, aun cuando se sirve de ella como criterio exegético, ya que por razones temporales no era de aplicación, y termina con una singular interpretación de lo establecido en los artículos 43.2 de la Ley 30/1992 y 242.6 del Texto Refundido de la Ley del Suelo de 1992, por entender que el significado de este último precepto no es otro que un mandato dirigido a la Administración y al solicitante de la licencia, que «intenta evitar que por el juego del silencio positivo se otorguen facultades contrarias al ordenamiento jurídico urbanístico», lo cual, según la propia Sala del Tribunal Superior de Justicia, «es, ni más ni menos, que un título habilitador para impugnar o revisar la licencia obtenida por silencio».

No comparte esta Sala del Tribunal Supremo ese parecer por las razones que seguidamente vamos a exponer, aunque no nos pasa desapercibido el conflicto que puede plantearse cuando la Administración no resuelve en tiem- 
po y después deniega una licencia si la obra, transcurrido el plazo para resolver, se ha iniciado o terminado a pesar de ser contraria a la legalidad urbanística, lo que generará, en supuestos de demolición, responsabilidades que, en cada caso, habrá que dirimir quién las deba soportar.

\section{CUARTO}

Vaya por delante que el artículo 8.1 b) del Texto Refundido de la Ley del Suelo de 2008 ha incorporado lo que disponía el artículo 242.6 del Texto Refundido de la Ley del Suelo de 1992 con una redacción más general.

Este, declarado expresamente vigente en la Disposición derogatoria única de la Ley 6/1998, de 13 de abril, y no derogado por la Disposición derogatoria única de la Ley $8 / 2007$, establecía que «en ningún caso se entenderán adquiridas por silencio administrativo licencias en contra de la legislación o del planeamiento urbanístico».

El artículo 8.1 b), último párrafo, del nuevo Texto Refundido de la Ley del Suelo, aprobado por Real Decreto Legislativo 2/2008, de 20 de junio, dispone que «en ningún caso podrán entenderse adquiridas por silencio administrativo facultades o derechos que contravengan la ordenación territorial o urbanística».

Uno y otro son preceptos estatales básicos de raigambre en nuestro ordenamiento urbanístico (artículo 178.3 del Texto Refundido de la Ley del Suelo de 1976), que rigen en todo el territorio español y que los ordenamientos urbanísticos autonómicos no pueden contradecir (Disposición final primera 1 del Texto Refundido aprobado por el citado Real Decreto Legislativo 2/2008, de 20 de junio).

\section{QUINTO}

También es un precepto estatal básico el contenido en el artículo 43.2 de la Ley de Régimen Jurídico de las Administraciones Públicas y Procedimiento Administrativo Común 30/1992, de 26 de noviembre, modificado por Ley 4/1999, de 13 de enero, según el cual «los interesados podrán entender estimadas por silencio administrativo sus solicitudes en todos los casos, salvo que una norma con rango de Ley o norma de Derecho Comunitario Europeo establezca lo contrario».

Pues bien, la regla general es la del silencio positivo, aunque la propia norma contiene la salvedad de que otra norma con rango de Ley o norma de 
Derecho Comunitario Europeo establezca lo contrario, y esto es lo que sucedía con la vigencia antes, en todo el territorio español, del precepto contenido en el aludido artículo 242.6 del Texto Refundido de la Ley del Suelo de 1992 y ahora con lo dispuesto en el artículo 8.1 b), último párrafo, del Texto Refundido de la Ley del Suelo de 2008, y, por consiguiente, conforme a ellos, no pueden entenderse adquiridas por silencio administrativo licencias en contra de la ordenación territorial o urbanística, de manera que la resolución de la Sala de lo Contencioso-Administrativo del Tribunal Superior de Justicia, al declarar lo contrario, es errónea y gravemente dañosa para el interés general porque elimina una garantía encaminada a preservar la legalidad urbanística.

\section{SEXTO}

Mantenemos, por tanto, la misma doctrina jurisprudencial que existía con anterioridad a la Ley 4/1999, que modificó el artículo 43.2 de la Ley 30/1992, de Régimen Jurídico de las Administraciones Públicas y del Procedimiento Administrativo Común, recogida, entre otras, en nuestras Sentencias de fechas 30 de enero de 2002 (recurso de casación 9239/97), 15 de octubre de 2002 (recurso de casación 11.763/98), 17 de noviembre de 2003 (recurso de casación 11768/98), 26 de marzo de 2004 SIC (recurso de casación 4021/01), 3 de diciembre de 2005 SIC (recurso de casación 6660/02), 31 de octubre de 2006 (recurso de casación 3289/03), 17 de octubre de 2007 (recurso de casación 9828/03) y 17 de octubre de 2007 (recurso de casación $9397 / 03)$, lo que corrobora el error de la Sala de instancia y la necesidad de que procedamos a declarar la doctrina legal que nos pide el Ayuntamiento recurrente, y que debemos hacer extensiva al artículo 8.1. b), último párrafo, del Texto Refundido de la Ley del Suelo aprobado por Real Decreto Legislativo 2/2008, de 20 de junio, con los efectos que establece el artículo 100.7 de la Ley de la Jurisdicción Contencioso-Administrativa, de manera que, respetando la situación jurídica particular derivada de la sentencia recurrida, a partir de la publicación de la parte dispositiva de esta nuestra en el Boletín Oficial del Estado, vinculará a todos los jueces y tribunales por ser la Sala Tercera del Tribunal Supremo, conforme a lo establecido en el artículo 123.1 de la Constitución, el órgano jurisdiccional superior en el orden contencioso-administrativo en toda España.

\section{SÉPTIMO}

Al ser estimable el recurso interpuesto, no procede, conforme a lo establecido en el artículo 139.2 de la Ley de esta Jurisdicción, formular expresa condena al pago de las costas procesales causadas. 
Vistos los preceptos y jurisprudencia citados, singularmente lo dispuesto en el artículo 100 de la vigente Ley Jurisdiccional.

\section{FALLAMOS}

Que, con estimación del recurso de casación en interés de la ley sostenido por el Procurador Don Juan Ignacio Ávila del Hierro, en nombre y representación del Ayuntamiento de Málaga, contra la sentencia pronunciada, con fecha 29 de marzo de 2007, por la Sala de lo Contencioso-Administrativo del Tribunal Superior de Justicia de Andalucía, con sede en Málaga, en el recurso de apelación 8/2003, debemos declarar y declaramos, sin afectar a la situación jurídica particular derivada de dicha sentencia, como doctrina legal que el artículo 242.6 del Texto Refundido de la Ley sobre Régimen del Suelo y Ordenación Urbana, aprobado por Real Decreto Legislativo 1/1992, de 26 de junio, y el artículo 8.1 b), último párrafo, del Texto Refundido de la Ley del Suelo aprobado por Real Decreto Legislativo 2/2008, de 20 de junio, son normas con rango de leyes básicas estatales, en cuya virtud y conforme a lo dispuesto en el precepto estatal, también básico, contenido en el artículo 43.2 de la Ley 30/1992, de 26 de noviembre de Régimen Jurídico de las Administraciones Públicas y del Procedimiento Administrativo Común, modificado por Ley 4/1999, de 13 de enero, no pueden entenderse adquiridas por silencio administrativo licencias en contra de la ordenación territorial o urbanística, sin hacer expresa condena respecto de las costas procesales causadas.

Así por esta nuestra sentencia, cuya parte dispositiva se publicará en el Boletín Oficial del Estado, lo pronunciamos, mandamos y firmamos, debiéndose hacer saber a las partes, al notificársela, que contra ella no cabe recurso ordinario alguno. PUBLICACIÓN.- Leída y publicada que fue la anterior sentencia por el Excmo. Sr. D. Jesús Ernesto Peces Morate, Magistrado Ponente en estos autos, de lo que como Secretario certifico. 